Bull. Mater. Sci., Vol. 21, No. 5, October 1998, pp. 387-391. (C) Indian Academy of Sciences.

\title{
Studies on $\mathrm{Ce}_{2}\left(\mathrm{C}_{2} \mathrm{O}_{4}\right)_{3} \cdot n \mathrm{H}_{2} \mathrm{O}$ crystals grown in hydro-silica gel
}

\author{
MERCY V JOHN ${ }^{\dagger}$ and M A ITTYACHEN* \\ School of Pure and Applied Physics, Mahatma Gandhi University, Kottayam 686 560, India \\ tDepartment of Physics, Mar Athanasius College, Kothamangalam 686666 , India \\ MS received 4 May 1998; revised 20 July 1998
}

\begin{abstract}
Single crystals of cerium oxalate are grown by the gel method. $\mathrm{Ce}\left(\mathrm{NO}_{3}\right)_{3}$ is allowed to diffuse into a gel in which oxalic acid is incorporated. Cerium oxalate crystals are formed by chemical reaction and the growth process is observed. Crystals are yellow-white in colour. Morphology and size of the crystals are highly influenced by the acidity of the feed solution. With $30 \% \mathrm{HNO}_{3}$ long needle shaped, with $50 \%$ $\mathrm{HNO}_{3}$ thin hexagonal and with $100 \% \mathrm{HNO}_{3}$, well developed crystals are obtained. Natural etch pits are observed on the grown crystals due to the presence of $\mathrm{HNO}_{3}$. Appearance of a single, large interfacial crystal is observed for $0.5 \mathrm{M}$ cerium nitrate. IR spectrum confirms the presence of water molecules and carboxylic group. X-ray diffractogram gives well defined peaks. Peaks are indexed. Unit cell dimensions are determined. Thermal analysis of the samples done using TGA and DTA show the release of water molecules (endothermic) and of $\mathrm{CO}$ and $\mathrm{CO}_{2}$ (exothermic) with the rare earth oxide as stable residue.
\end{abstract}

Keywords. Cerium oxalate crystals; gel growth; optical and IR spectroscopy; XRD; TGA; DTA.

\section{Introduction}

Cerium is unique among other rare-earth metals with only a single electron in the $4 f$ shell when it is in ionic state. Its optical, luminescent and magnetic properties are studied widely. $\mathrm{Ce}^{3+}$ is used as a co-dopant in certain photo refractive crystals like $\mathrm{LiNbO}_{3}, \mathrm{KNbO}_{3}$ and $\mathrm{Sr}_{x} \mathrm{Ba}_{1-x} \mathrm{Nb}_{2} \mathrm{O}_{6}$ (Raj Kamal et al 1992) and laser crystals like $\mathrm{Y}_{3} \mathrm{Al}_{5} \mathrm{O}_{12}: \mathrm{Nd}$ and $\mathrm{YAlO}_{3}: \mathrm{Nd}$ (Mares 1991). Several compounds containing cerium are under study for their ferromagnetic, antiferromagnetic and superconducting properties. Optical and luminescent properties of laser scintillator crystals like YAG and YAP doped with $\mathrm{Ce}^{3+}$ ions are studied (Rao 1992). No report has been noticed on the study of cerium oxalate. Hence growth of this crystal is attempted. Cerium oxalate can be grown by gel technique since it has very low solubility in water. Growth and characterization of several oxalates and mixed rare-earth oxalates in silica gel have already been reported (Shedam and Venkateswara Rao 1993; Cyriac Joseph et al 1995; Varghese John et al 1997). Grown crystals are characterized by different methods.

\section{Experimental}

Solution of sodium meta silicate in double distilled water has been prepared with a density of $1.03 \mathrm{~g} / \mathrm{cc}$. This solution is poured into a clean glass test tube of $15 \mathrm{~mm}$ inner diameter and $150 \mathrm{~mm}$ in length. Over this solution

\footnotetext{
*Author for correspondence
}

1 molar oxalic acid solution is added until the mixture attains a $\mathrm{pH}$ of 6 . At this $\mathrm{pH}$, gelling is completed within two days. Over this fully gelled mixture, 0.5 cerium nitrate acidified with conc. $\mathrm{HNO}_{3}$ is poured carefully and kept undisturbed. Cerium nitrate solution is found to diffuse slowly through the gel reacting with the oxalic acid already incorporated in the medium. Reaction will take place according to the equation,

$$
2 \mathrm{Ce}\left(\mathrm{NO}_{3}\right)_{3}+3 \mathrm{H}_{2} \mathrm{C}_{2} \mathrm{O}_{4} \rightarrow \mathrm{Ce}_{2}\left(\mathrm{C}_{2} \mathrm{O}_{4}\right)_{3} \cdot n \mathrm{H}_{2} \mathrm{O}+6 \mathrm{HNO}_{3} \text {. }
$$

Insoluble cerium oxalate crystals are formed due to this reaction. The gel medium prevents turbulence and being chemically inert, it provides a three-dimensional structure which permits reagents to diffuse at a controlled rate. This experiment has been conducted at ambient temperature. Initially nucleation centres are found to occur starting from $1 \mathrm{~cm}$ below the gel interface. Already formed nuclei then continued to grow for three weeks and growth tapered off afterwards. Number, size and morphology of crystals varied with gel density, $\mathrm{pH}$, concentration of feed solution, acidity of feed solution and strength of oxalic acid.

\section{Observations and investigations}

\subsection{Optical microscopic studies}

Crystals grown under different conditions are collected and observed under Carl-Zeiss metallurgical microscope. Yellow-white transparent crystals with well developed 
faces together with a few opaque crystals are observed. The morphology of crystals are found to vary according to the conditions of growth. With $30 \% \mathrm{HNO}_{3}$ long thin crystals - clusters as well as single ones-are obtained. As the strength of the acid increases, they become thin plates and finally have a thick cubical or hexagonal shape. Figure 1 shows a well developed crystal. Closer examination under the microscope shows that the faces are plane in the case of hexagonal crystals and striations are observed on long ones. Some of the crystals are found to be etched heavily (figure 2). Etching may be caused by $\mathrm{HNO}_{3}$ present in the medium. Shallow and deep etch pits are formed. Deeper ones may be due to dislocation present in the crystal.

Marked difference in number and size of the crystals is observed for crystals grown under different concentrations of the feed solution. Number of crystals decreases with decrease in concentration. In the case of $2 \mathrm{M}$ and $1 \mathrm{M}$ feed solutions, number of crystals decreases and

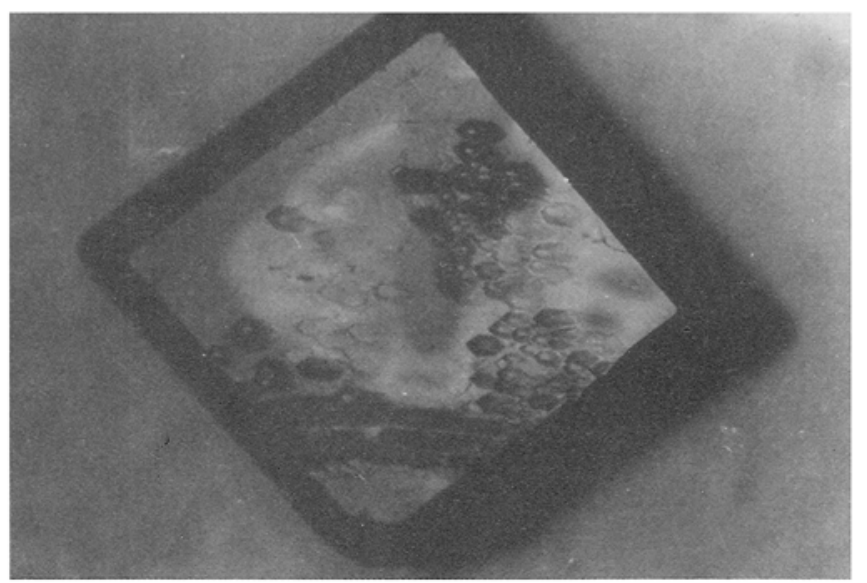

Figure 1. Crystal grown with $100 \% \mathrm{HNO}_{3}(\times 50)$.

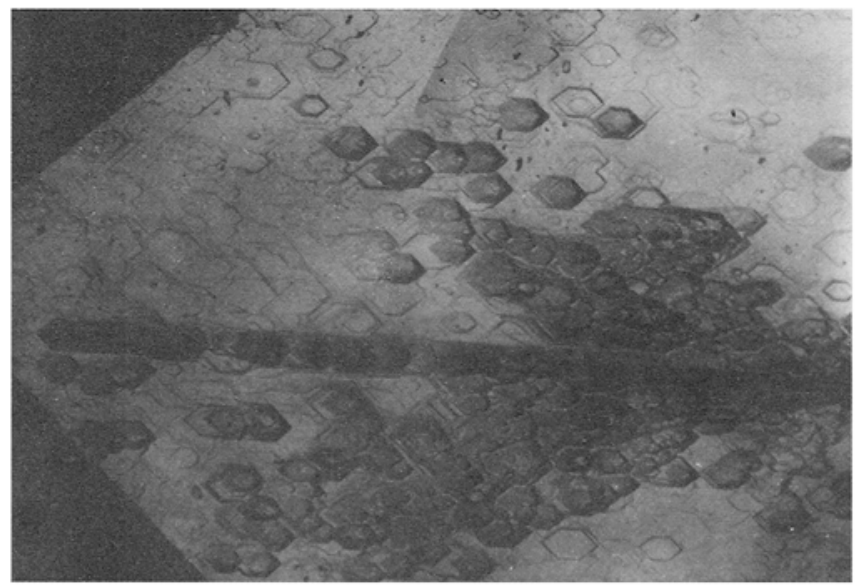

Figure 2. Natural etch pits on grown crystals $(\times 100)$. size increases towards the bottom of the test tube. For $0.5 \mathrm{M}$ and $0.25 \mathrm{M}$ feed solutions, large sized crystals are formed in the upper region of the crystallization zone and size decreases towards the bottom. Diffusion of the reacting ions from the feed solution depends on its concentration. In higher concentrations, chances for nucleation are greater in the upper layer itself resulting in large number of crystals and less spacing between growing crystals which minimize size of the crystals. But towards bottom layers, less nucleation occur, but sufficient ions are present for the crystals to grow in large size.

In lower concentrations of the feed solution $(0.5 \mathrm{M}$ and $0.25 \mathrm{M}$ ), chances of nucleation are less in the upper layer of the crystallization zone and more space and more ions are available for the growing crystals. So they become large in size. Towards bottom, nucleation is still less and due to the lack of reacting ions, their size is also small. This observation indicates that a particular minimum concentration of the reacting ions is necessary for nucleation.

Occasionally it is observed that single as well as cluster of crystals are found to grow at the gel interface. Figure 3 shows a typical case of such a single crystal grown in $0.5 \mathrm{M}$ cerium nitrate solution. This is due to the diffusion of oxalate ions upwards through the gel and reaction with cerium ions in the supernatant solution. It requires more time for the formation of a nucleus on the interface (about 10 days). The slow diffusion restricts the number of nuclei and once a nucleus is formed it became large in size because of the large availability of $\mathrm{Ce}^{3+}$ ions in the solution.

Distance of crystallization zone from the gel interface is also different with difference in concentration of the

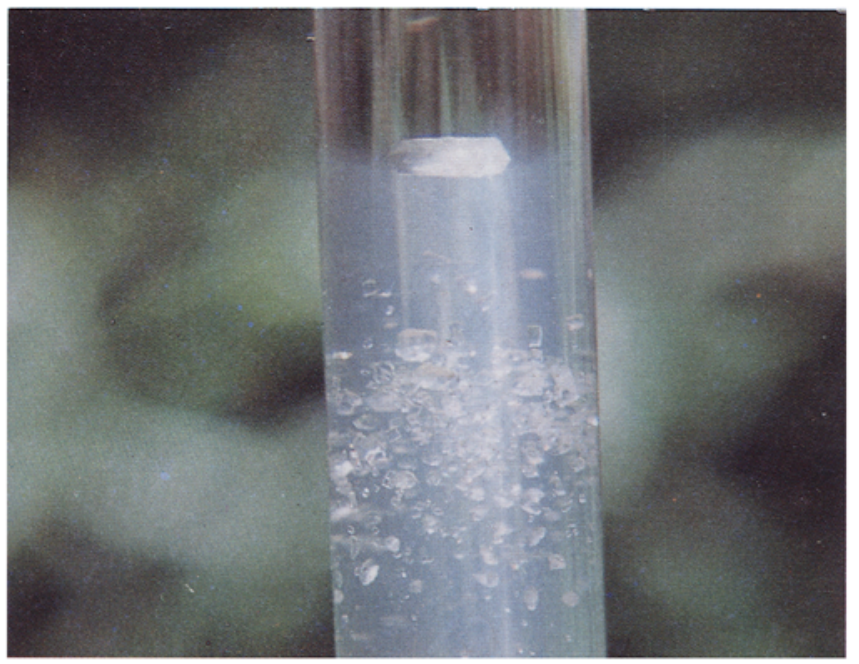

Figure 3. A single large interfacial crystal for $0 \cdot 5 \mathrm{M}$ cerium nitrate $(\times 2)$. 
feed solution. For higher concentrations, it is just $1 \mathrm{~cm}$ below the gel interface and this distance increases up to $2 \mathrm{~cm}$ for lower concentration. This distance may be indicating the formation of supersaturation of the reacting ions in different cases inside the gel.

\subsection{Spectral studies-IR spectra}

A Shimadzu IR-470 spectrometer is employed to obtain infrared absorption spectrum using $\mathrm{KBr}$ pellet method (figure 4).

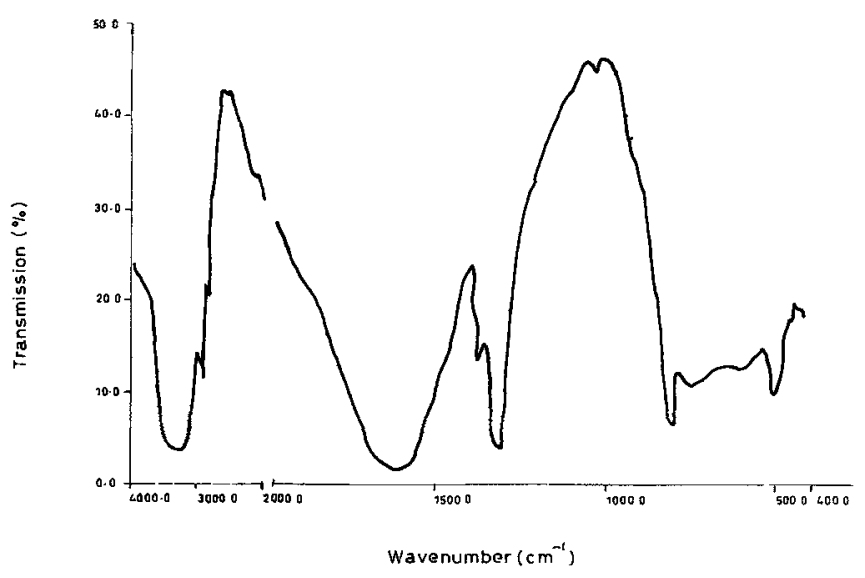

Figure 4. IR spectrum of cerium oxalate.
The crystal has water of crystallization which is evidenced by the intense broad peak at $3500-3200 \mathrm{~cm}^{-1}$. $1620-1600 \mathrm{~cm}^{-1}$ relate to bending mode of water and asymmetric stretch of $\mathrm{CO}_{2}$ (Petrov and Soptrajanov 1975). $1360 \mathrm{~cm}^{-1}$ and $1310 \mathrm{~cm}^{-1}$ correspond to $\mathrm{CO}_{2}$ symmetric stretch. The sharp IR band observed at $800 \mathrm{~cm}^{-1}$ has been assigned to $\mathrm{M}-\mathrm{O}$ band where $\mathrm{M}=\mathrm{Ce}$ (Fujita et al 1962). $490 \mathrm{~cm}^{-1}$ represent the $\mathrm{CO}_{2}$ wagging mode (Cyriac Joseph et al 1997).

\subsection{X-ray powder diffractometry}

$\mathrm{X}$-ray diffraction pattern of the sample obtained using Philips PW $1710 \mathrm{X}$-ray generator is shown in figure 5 . Patterns are recorded using $\mathrm{Ni}$ filtered $\mathrm{CuK} \alpha$ radiation. Well defined Bragg peaks at specific $(2 \theta)$ angles indicate the crystallinity of the samples. The observed $d$ values are found to agree with the calculated $d$ values.

The XRD patterns are indexed using least square program LATPAR. The indexing results seem to be very accurate as the difference involved in $d(\mathrm{obs})$ and $d$ (cal) as well as error $( \pm)$ in the values of cell parameters are very small. The unit cell dimensions are $9.96213 \AA$, $11.9533 \AA, 13.15118 \AA$ for orthorhombic system and unit cell volume is $1566.056 \AA^{3}$.

\subsection{Thermal analyses (TGA and DTA)}

TGA and DTA data are obtained on $18 \mathrm{mg}$ and $30 \mathrm{mg}$

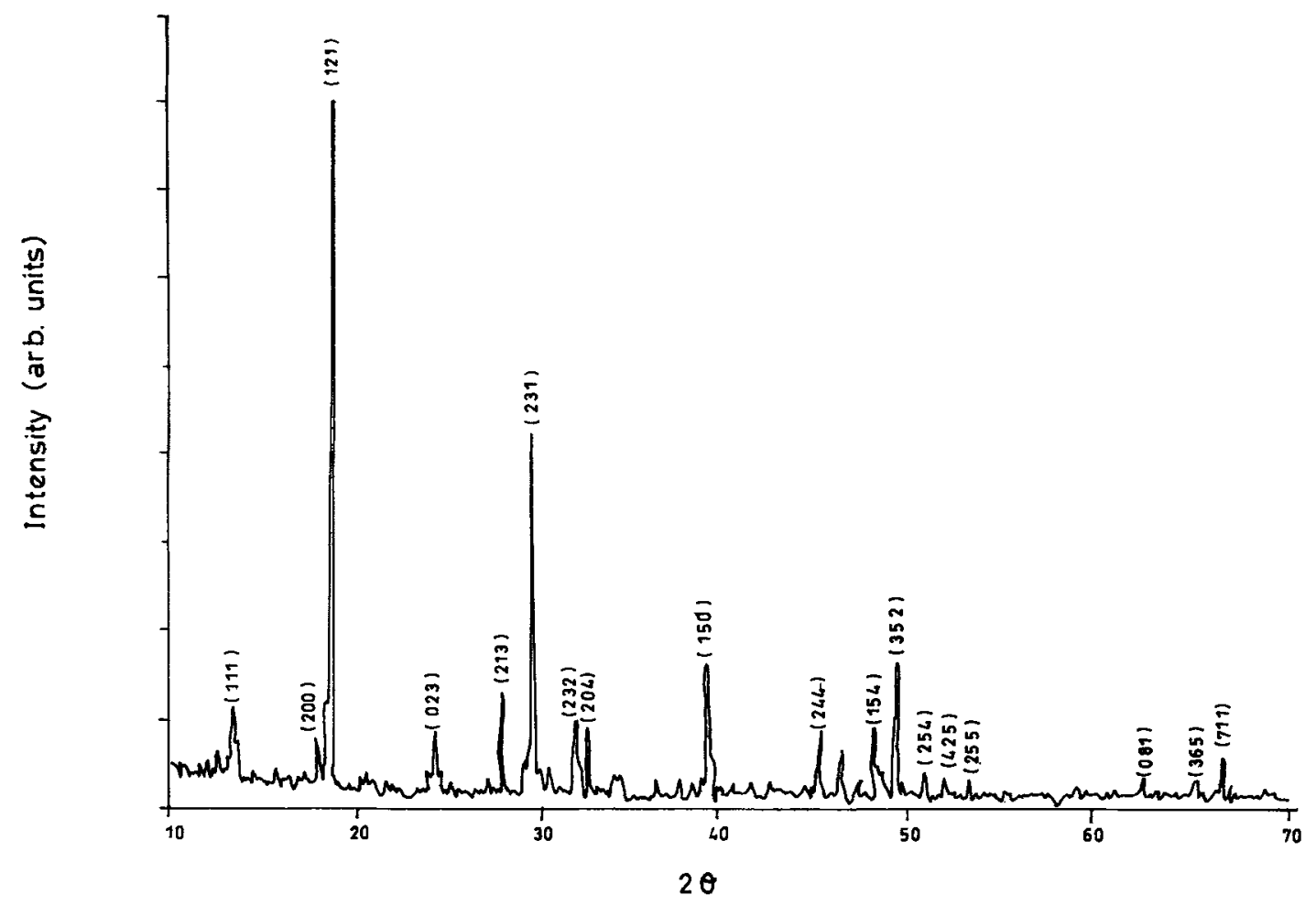

Figure 5. X-ray powder diffractogram of $\mathrm{Ce}_{2}\left(\mathrm{C}_{2} \mathrm{O}_{4}\right)_{3} \cdot n \mathrm{H}_{2} \mathrm{O}$. 
Table 1. Thermal analysis results of $\mathrm{Ce}_{2}\left(\mathrm{C}_{2} \mathrm{O}_{4}\right)_{3} \cdot n \mathrm{H}_{2} \mathrm{O}$.

\begin{tabular}{lccccc}
\hline & $\begin{array}{c}\text { Decomposition } \\
\text { temp. }\left({ }^{\circ} \mathrm{C}\right)\end{array}$ & $\begin{array}{c}\text { Loss of } \\
\text { material }\end{array}$ & $\begin{array}{c}\text { Observed } \\
\text { mass loss } \\
(\%)\end{array}$ & $\begin{array}{c}\text { Calculated } \\
\text { mass loss } \\
(\%)\end{array}$ & Endo/exo \\
\hline Stage 1 & $50^{\circ} \mathrm{C}-220^{\circ} \mathrm{C}$ & $9 \mathrm{H}_{2} \mathrm{O}$ & 22.22 & 22.94 & endo \\
Stage 2 & $220^{\circ} \mathrm{C}-555^{\circ} \mathrm{C}$ & $3 \mathrm{CO}+3 \mathrm{CO}_{2}$ & 30.00 & 30.59 & exo \\
\hline
\end{tabular}

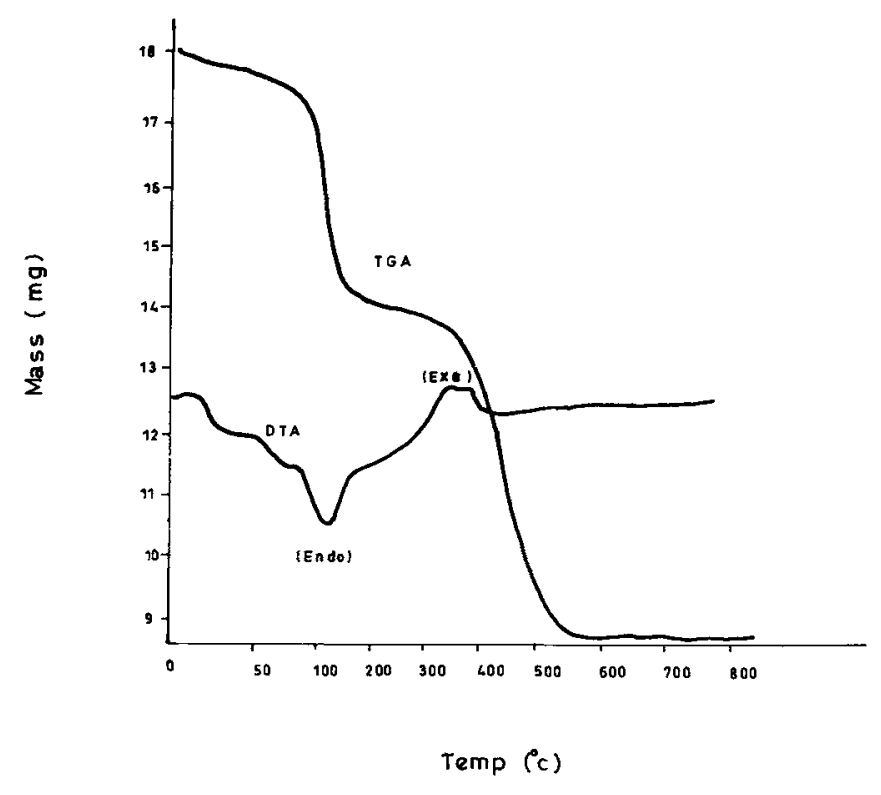

Figure 6. TGA and DTA plots of cerium oxalate.

samples, respectively by scanning at $5^{\circ} \mathrm{C} / \mathrm{min}$ under the atmosphere of argon. Thermogravimetric runs were taken on Shimadzu thermobalance and runs were taken on DTA set up coupled with Rikadenki multiplier recorder and endotherm temperature programmer (figure 6).

Cerium oxalate is characterized by the loss of the bulk of water of crystallization in a single peaked endotherm in the range $100^{\circ} \mathrm{C}-200^{\circ} \mathrm{C}$. Complete dehydration is only on the onset of oxalate decomposition as observed by Fuller et al (1980). DTA curve in the region $325^{\circ} \mathrm{C}-400^{\circ} \mathrm{C}$ is characterized by an exothermic peak which shows the oxalate decomposition.

The loss of weight in the temperature range $50^{\circ} \mathrm{C}-$ $220^{\circ} \mathrm{C}$ relates to the loss of water of crystallization (endothermic reaction) as follows:

$$
\mathrm{Ce}_{2}\left(\mathrm{C}_{2} \mathrm{O}_{4}\right)_{3} \cdot 9 \mathrm{H}_{2} \mathrm{O} \stackrel{-9 \mathrm{H}_{2} \mathrm{O}}{\longrightarrow} \mathrm{Ce}_{2}\left(\mathrm{C}_{2} \mathrm{O}_{4}\right)_{3}
$$

Loss of weight in the temperature range $220^{\circ} \mathrm{C}-555^{\circ} \mathrm{C}$ relates to the release of $\mathrm{CO}$ and $\mathrm{CO}_{2}$ which are exothermic in character. The chemical reaction is as follows:

$$
\mathrm{Ce}_{2}\left(\mathrm{C}_{2} \mathrm{O}_{4}\right)_{3} \stackrel{-\left(3 \mathrm{CO}+3 \mathrm{CO}_{2}\right)}{\longrightarrow} \mathrm{Ce}_{2} \mathrm{O}_{3}
$$

Beyond $555^{\circ} \mathrm{C}$ the residue mainly consists of $\mathrm{Ce}_{2} \mathrm{O}_{3}$ which is fairly stable.

Results can be tabulated as given in table 1. Observed mass loss correspond to the loss of $9 \mathrm{H}_{2} \mathrm{O}$.

\section{Conclusions}

(i) The gel grown cerium oxalate sample reported in the present work is yellow-white in colour and is crystalline in nature as evidenced by the well defined edges and corners as well as by the natural etch pits on the surface (figures 1 and 2) and by X-ray diffractometry. The unit cell parameters from $X$-ray analysis are $a=9.96213 \AA$, $b=11.95337 \AA, c=13.15118 \AA$ and $\alpha=\beta=\gamma=90^{\circ} \mathrm{C}$.

(ii) Presence of water molecules in the sample is evidenced by the peaks at $3600 \mathrm{~cm}^{-1}$ and $3200 \mathrm{~cm}^{-1}$.

(iii) Presence of carboxylic group is evidenced by the peaks at $1600 \mathrm{~cm}^{-1}$ and $1300 \mathrm{~cm}^{-1}$.

(iv) Loss of $9 \mathrm{H}_{2} \mathrm{O}$ from $\mathrm{Ce}_{2}\left(\mathrm{C}_{2} \mathrm{O}_{4}\right)_{3} \cdot 9 \mathrm{H}_{2} \mathrm{O}$ is proved from the thermal analysis by the dehydration around $180^{\circ} \mathrm{C}$ (endothermic) and the evolution of $\mathrm{CO}$ and $\mathrm{CO}_{2}$ around $350^{\circ} \mathrm{C}$ (exothermic), yielding stable residual rare earth oxide beyond $555^{\circ} \mathrm{C}$.

\section{Acknowledgements}

Authors are thankful to Dr P N Moorthy, Dr A K Thyagi and $\operatorname{Dr} M$ D Mathews, Applied Chemistry Division, BARC, Mumbai, for their valuable help in obtaining the X-ray powder diffraction data. Authors are also thankful to Dr A B Phadnis and Dr S R Dharwadkar, Applied Chemistry Division, BARC, Mumbai for their valuable help in obtaining thermal analysis data.

\section{References}

Cyriac Joseph, George Varghese and Ittyachen M A 1995 Cryst. Res. Technol. 30159

Cyriac Joseph, Ittyachen M A and Raju K S 1997 Bull. Mater. Sci. 2037

Fujita J, Martell A E and Nakamoto K 1962 J. Chem. Phys. 36324

Fuller M J and Pinkstone J 1980 J. Less-Conmon Metals 70127 
Mares J A 1992 Second international school of excited states of transition elements, Karpacz, Poland (Singapore: World Scientific) p. 192

Petrov I and Soptrajanov B 1975 Spectrochimica Acta A31 309

Raj Kamal, Maheswari K P and Sawhney R L 1992 Laser optics-Reviews in contemporary physics (New Delhi: Wiley Eastern Ltd).
Rao R P 1992 Second international school on excited states of transition elements, Karpacz, Poland (Singapore: World Scientific) p. 231

Shedam M R and Venkateswara Rao A 1993 Bull. Mater. Sci. 16309

Varghese John, Ittyachen M A and Raju K S 1997 Bull. Mater. Sci. 201059 